\title{
Blended learning in design education: An analysis of students' experiences within the disciplinary differences framework
}

\author{
Şule Taşlı Pektaş, Meltem Ö. Gürel \\ Bilkent University, Turkey
}

\begin{abstract}
Blended learning has already become an indispensable part of education in many fields. However, the majority of existing research on blended learning has assumed homogeneity of disciplines. This study suggests that research highlighting disciplinary effects and differences is much needed to effectively develop courses and tools consonant with the characteristics of each discipline. To help close this research gap, this paper focuses on design education and analyses student experiences in a "blended design studio" that combined the Moodle learning management system, live videoconferencing, and social networking media (Facebook) with traditional face-to-face learning (design studio). Students' perceptions of the methods and tools were elicited through structured and openended questions and qualitative variations in responses were categorised. Subsequent quantitative analysis revealed that the characteristics of soft-applied fields require customisation in blended courses and educational system designs in several ways.
\end{abstract}

\section{Introduction}

In spite of the ever-growing body of empirical research on online and blended learning, analyses of these approaches in different disciplines and educational contexts are not numerous (Arbaugh, Bangert \& Cleveland-Innes, 2010; Smith, Passmore, \& Faught, 2009). This research gap can be attributed to the methodological conceptualisations applied in related research, which have often addressed content issues generically without paying particular attention to the disciplinary effects. However, each discipline has unique characteristics that may have important implications for educators and educational system developers. Furthermore, insights into what is common for all blended learning modules and what is specific for applications in particular disciplines will help strengthen theory-forming processes in the field.

A traditional way of classifying different disciplines is to distinguish between hard and soft fields of learning (Biglan, 1973). Hard fields consist of the natural sciences, medicine, and technology; the humanities and most of the social sciences are considered soft fields. According to Biglan's taxonomy (1973), academic disciplines can also be categorised on the basis of whether a discipline has a focus on application or involves real-world problem-solving (applied), or places more attention on knowledge acquisition (pure). Neumann (2001) and Neumann, Parry, and Becher (2002) categorised disciplines in a quadrant (hard-pure, hard-applied, soft-pure, and soft-applied) and defined particular characteristics of each type with respect to curriculum, teaching, and assessment. They claimed that a sound understanding of key aspects of teaching and learning depends on the distinctive features of different knowledge domains and their social environments.

A review of literature about online and blended learning reveals that studies in soft-applied fields like design education have been rather limited. Design education can be conceptualised as teaching and learning theory and application for designing products, services, and environments. It encompasses various subdisciplines such as engineering design, architectural design, graphic design, interaction design, interior design, industrial design, and fashion design. As a soft-applied discipline, design education requires a formative and reiterative learning process, which includes qualitative, constructive, and interpretative activities. Moreover, it consists of a particular way of learning-by-doing and extensive project-based learning. Design is a multidisciplinary activity, thus its education should ideally involve collaboration and teamwork (Pektas, 2007). For the above reasons, the present study was designed as a project-based global teamwork experience. A global team can be defined as a temporary, digitally mediated, culturally diverse, and geographically distributed group of peers who collaborate in a shared project (Kristof, Brown, Sims \& Smith, 1995). Several advantages of using such teams for teaching and learning have been highlighted, such as sharing a variety of ideas about, perspectives on, and approaches to problem solving, creativity, and cognitive and social development (Karakaya \& Pektas, 2007). 
According to Ginns and Ellis (2009), a central aspect of teaching and learning is the students' own experiences of the process. However, published work on blended learning has focused more on different methods of teaching and on the innovations introduced rather than on student experiences (Lopez-Perez, Perez-Lopez \& Rodrigues-Ariza, 2011; Paechter \& Maier, 2010). This study therefore investigated students' perceptions of blended learning methods and tools in a domain-specific context and analysed an exploratory blended learning setting that utilised face-to-face and one-to-one learning (traditional design studio), the Moodle learning management system (LMS), live videoconferencing, and social networking media (Facebook). It was hypothesised that a combination of synchronous and asynchronous tools with different representational capabilities would complement each other and create a positive learning environment.

This paper analyses the experiences of design students in a blended learning environment where traditional face-to-face education was combined with online distance education techniques. The study explored the following research questions:

1. What are design students' preferences for blended, online, and face-to-face learning?

2. How do students perceive face-to-face learning in the design studio and the use of online education tools (the LMS as an interaction platform, the LMS as course repository, live videoconferencing, and social networking media) in a blended learning environment in design education?

3. How can a blended learning approach be utilised effectively in soft-applied disciplines?

The disciplinary differences framework proposed by Neumann, Parry, and Becher (2002) is used to discuss the findings.

\section{Theoretical background}

\section{Research on disciplinary differences in online and blended learning}

Although there is no consensus on the usage of the term, "blended learning" is generally defined as the integration of traditional face-to-face learning with online learning, making it possible to benefit from the advantages of both teaching methods (So \& Bonk, 2010). It has been increasingly recognised that online and blended learning should be studied through the disciplines paradigm as defined by Neumann, Parry, and Becher (2002), focusing on the disciplinary effects. There have been some studies in this track in mathematics education (Trenholm, 2006), in business education (Arbaugh et al., 2010), and in nursing education (Smith et al., 2009). There have also been a few comparative studies. For example, Hornik, Saunders, Li, Moskal \& Dzuiban (2008) found that student grades were significantly higher and withdrawal rates were lower for courses in hard disciplines compared to those in soft disciplines in online education. Considering the limited number of studies on disciplinary effects in online education, the results of existing research are not yet conclusive. Therefore, several studies in this track called for further studies (Smith et al., 2009; Arbaugh et al., 2010).

\section{Design education}

The framework for disciplinary differences proposed by Neumann (2001) and Neumann et al. (2002) provides a useful ground to discuss the characteristics of design education. According to this framework, soft-applied disciplines "are concerned with the accumulation of knowledge by a reiterative process shaped by practically honed knowledge and espoused theory" (Neumann et al., 2002, p. 408). Since students' performance evaluations are typically ambiguous due to the vast amount of practical and inexplicit skills students are expected to demonstrate, there is more need for peer and self-assessment as well as for constructive and interpretative feedback on assessment tasks. Unlike hard disciplines, evaluation is not based on explicit criteria but on an implicit and often subjective process. Students are ultimately assessed in terms of their readiness to begin a professional career closely related to their field of study. 
Design education typically represents all characteristics of a soft-applied discipline, with a particular focus on reflective practice and project-based learning. "Reflective practice" is a term coined by Schön (1983) and defined as "a dialogue of thinking and doing through which [students] become more skilled" (Schön, 1987). Reflective practice is a mode of professional education that refers to the capacity to reflect on action so as to engage in a process of continuous learning. It is one of the defining characteristics of professional practice and practice-based professional learning settings, where individuals learn from their own professional experiences rather than from formal teaching or knowledge transfer.

Another characteristic of design education is its authentic project-based learning (PBL) approach. Projectbased learning is an educational strategy through which students are encouraged to learn via "real-life" problem solving. It often involves teamwork or collaborative learning whereby students work cooperatively with their peers and interact socially to discuss and develop ideas to solve a realistic problem. The PBL method has many features of the constructivist learning model because it entails that students become active participants in the learning process and that they "learn how to learn" (ArdaizVillanueva, Nicuesa-Chacon, Brene-Artazcoz, Lizarraga \& Baquedano, 2011).

The design studio is the traditional mode of learning in design education. It is essentially a shared environment in which students are assigned problems and projects to solve individually or collaboratively. The studio is widely accepted as the nucleus of the curriculum because of its structure and content that combines various curricular topics within a design project. A studio project gives students opportunities to test and share their ideas with instructors and classmates at theoretical and practical levels (Gürel, 2010). Students respond to the design project through critiques and are expected to share their proposed solutions, development processes, and final presentations with other students and with teachers. Although the design process can be very personal because of the creative nature of design, this interactive environment also allows exchange of knowledge and ideas among individuals. Therefore, the studio provides a dynamic discussion medium that engages students both academically and socially. As Schön (1988, p. 5) argues, the studio works as "a virtual world representing the real world of practice, but relatively free of its pressures and risks." Accordingly, the studio environment holds the capacity for better preparing students for professional practice while giving them a holistic view and enriching their pedagogical experience (Türkkan, Basa \& Gürel, 2010). This role of the design studio coincides with Neumann, Parry, and Becher's (2002, p. 412) definition of learning environments in soft-applied fields as "simulated professional work."

\section{Blended learning in design education}

Blended learning has already been widely used in many disciplinary domains but its applications in design education are relatively new. Bender and Vredevoogd (2006) demonstrated an early example of blended learning in design education. They created a course website to share educational materials and faculty members were available outside of lecture hours via e-mail and web-based conferencing. The authors concluded that blended learning would enhance design studio courses.

There have also been earlier attempts to integrate LMS' with design education. Novakova, Achten, and Matejovska (2010) used Moodle for teaching collaborative design in a studio course. They concluded that although Moodle provided a useful platform for this purpose, it was not appropriate for direct collaboration through real-time sharing of documents. Park (2011) combined Blackboard with traditional teaching methods in two course modules on visual and communication design. The author commented that design education has not been researched extensively with regard to online learning and that further studies are needed to integrate online techniques with design education. Pektas and Demirkan (2011) utilised Moodle as a communication tool for design teamwork and found that the usability of the tool was satisfactory. Based on their findings, the researchers recommended further experiments with Moodle in design courses.

The use of social networking media in design education is newly emerging. Adams, Hyde, and Murray (2013) defined this media as a key factor that would change design education and called for studies on it. Ham and Schnabel (2011) implemented a design studio that incorporated a social networking site (Ning.com). They found that social networking technology offers new opportunities for design education through removing professional, institutional, and national boundaries. It should be noted that none of these studies used the disciplinary differences perspective to discuss their results. 


\section{Methodology}

\section{Research setting and participants}

The participants in the current study were from the Department of Interior Architecture and Environmental Design at Bilkent University in Ankara, Turkey. The research was conducted in a workshop implemented as a part of the fourth-year design studio in Spring 2011. Forty-five students participated and 42 (30 females and 12 males) returned complete assessments, which were analysed and included in the analysis. Participant ages ranged from 21 to 26, with the mean age $22.87(\mathrm{SD}=1.47)$.

\section{Procedures}

Media comparison studies have often been criticized on methodological concerns, such as their inability to disentangle the effects of delivery modes, instructor and learner characteristics, and instructional methods (Howsen \& Lile, 2008; Joy \& Garcia, 2000). In this study, methodological drawbacks were minimised by the workshop and research design. The workshop spanned five weeks of the semester and consisted of two modules, which enabled comparing different delivery modes in a single project with the same group. The first module utilised only traditional face-to-face teaching and the second module comprised a blended approach, using traditional and online distance education techniques. In the first module, students formed groups of five and each group was required to design a partially self-sufficient living unit in a specific climatic zone. The groups researched topics related to the project, presented them to the class, produced initial design ideas, and discussed their projects with the instructors. In the second module, each team was paired online with two students from the Department of Interior Design at East Carolina University in the United States, who worked as consultants for the group for the rest of the project.

Throughout the workshop, the LMS was used both as an interaction platform (discussion forums, announcements, etc.) and as a course repository for all resources related to the project, such as the project brief, research studies, and evaluation criteria. Collaborative work across the groups took place on the LMS discussion forums and on Facebook as asynchronous online text communication as well as through sharing images and drawings related to the projects. In this study, social networking media was not devised as a collaboration tool at the beginning; however, when it was observed that most participants used Facebook, the authors decided to include it in the survey. In addition to the discussion forums, news and announcements were also shared through Moodle's messaging system. Four videoconference sessions were organized in the second module. Half the sessions were interactive lectures while the other half was interactive project discussions. The live videoconferencing system was of room type and included two large flat screens, cameras, and microphones to communicate to the other similarly equipped conference room in the US. The system provided simultaneous video, voice, and file transmission between the two groups over the Internet and operated in continuous presence mode so that both groups were displayed at the same time.

\section{Data collection and analysis}

To analyse student views on the methods and tools utilised, qualitative and quantitative approaches were applied. Two questionnaires (one with closed questions and the other with open questions) were made available for all students who participated in the workshop. Closed questions were asked to collect data on demographics and preferences for blended, purely online, and purely traditional learning environments. Open questions were asked to investigate students' experiences in blended learning generally and with reference to the different tools utilised in the study. Both questionnaires were paperbased and administered together in a single session. The open questions were designed within the framework of the phenomenographic tradition of research on learning and teaching in higher education, which describes learning in terms of the "experience of learning" (Marton \& Booth, 1997). Building upon this track of research, this study's investigations focused on qualitative differences in the way students perceive and approach different tools in blended learning contexts. Response analysis was conducted using an established phenomenographic procedure (Yang \& Tsai, 2010). The participants' answers were pooled and analysed independently by the two authors. Emerging themes were identified and then discussed to reach a consensus. Discussion and refinement of the thematic categories were an iterative 
process and continued until total agreement was reached. The same procedure was applied for all questions. To conduct quantitative analyses, students' responses were assigned to one or more categories. The final categories, their distributions, and the illustrative quotes from participants ascribed to the particular categories are presented in Tables 2 to 7.

\section{Results}

\section{Participant background}

The participants were asked to indicate their level of computer experience on a five-point Likert scale, in which higher values denoted more computer experience. The results showed that the students rated themselves as experienced computer users $(X=4.44, \mathrm{SD}=0.59)$. The students were familiar with the Moodle LMS; all of them reported that they had used Moodle in at least one other course. All students had a Facebook account before the study and were regular users. The percentage distribution of the participants' daily Facebook use was as follows: 33\% of the participants: less than one hour; $57 \%$ of the participants: one to one-and-a-half hours; and 10\% of the participants: more than two hours. Among the several tools utilised in the study, the room type videoconferencing was the only one new to the participants; no participant indicated that he/she had previously used the videoconferencing facility.

\section{Comparison of blended, online, and traditional face-to-face learning}

After the workshop, participants were asked to rank purely online, purely traditional, and blended learning environments in terms of their appropriateness in design education. Sixty-one percent of the responses indicated that blended learning environments were the most appropriate for design education. Purely traditional learning environments ranked second, at $49 \%$, and $54 \%$ of the respondents reported that purely online learning environments were the least appropriate for design education (Table 1).

Table 1

Comparison of blended, online, and traditional face-to-face learning in design education

\begin{tabular}{|c|c|c|c|c|c|c|}
\hline & \multicolumn{2}{|c|}{ 1: Most appropriate } & \multicolumn{2}{|c|}{ 2: In between } & \multicolumn{2}{|c|}{ 3: Least appropriate } \\
\hline & $\mathrm{n}$ & $\%$ of responses & $\mathrm{n}$ & $\%$ of responses & $\mathrm{n}$ & $\%$ of responses \\
\hline Purely online & 9 & 22 & 10 & 24 & 22 & 54 \\
\hline Purely traditional & 7 & 17 & 20 & 49 & 14 & 34 \\
\hline Blended & 25 & 61 & 11 & 27 & 5 & 12 \\
\hline
\end{tabular}

\section{Respondents' views on their use of the LMS as an interaction platform}

The LMS as an interaction platform was found to be useful and easy to use. Several students indicated that the LMS enabled them to monitor other groups' processes and files. There were some suggestions for improvement in the LMS discussion forums, such as a more visual/intuitive interface, more synchronous communication, and instant messaging capability. The participants suggested that such changes in the LMS discussion forums would facilitate better exchange of design information (Table 2). 
Table 2

Respondents' views on their use of the LMS as an interaction platform

$\mathrm{n} \%$ of Illustrative quotations responses

The LMS as an interaction $\quad 20 \quad 57 \quad$ "The LMS was a very good platform for us to
platform was useful/easy to communicate easily." communicate with.

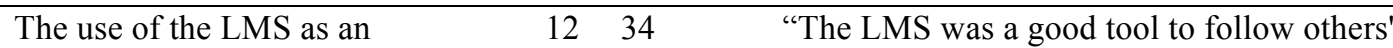
interaction platform was good because it enabled monitoring other groups' processes/files. projects and files with."

"The discussion forums were the most efficient in terms of observing the other groups and their developments."

\begin{tabular}{llll}
\hline $\begin{array}{l}\text { Some technical problems (in } \\
\text { downloading/uploading files, }\end{array}$ & 9 & 26 & $\begin{array}{l}\text { "It is a really good, efficient tool, but there } \\
\text { were some problems when we wanted to } \\
\text { connections, etc.) soured the }\end{array}$
\end{tabular}
experience.

\begin{tabular}{llll}
\hline $\begin{array}{l}\text { The LMS discussion forums were } \\
\text { not visual/intuitive enough. }\end{array}$ & 23 & $\begin{array}{l}\text { "I couldn't easily understand others' design } \\
\text { ideas with that technology. Maybe something } \\
\text { more visual would work better." }\end{array}$
\end{tabular}

$\begin{array}{llll}\text { Synchronous communication } & 7 & 20 & \text { "The LMS is designed for all students in the }\end{array}$ instead of asynchronous school, but a design student may require more. communication in the LMS would The LMS sometimes was not enough to have been better. communicate with. A system that enables us to work simultaneously might be better."

Announcement functionality of the $4 \quad 11$ "About the announcements, the LMS is a LMS was especially useful. $\quad$ really successful platform. I believe that every instructor should use the LMS system."

\begin{tabular}{lllll}
\hline $\begin{array}{l}\text { The discussion forums were not } \\
\text { good because one had to write } \\
\text { everything down and it was } \\
\text { difficult to follow the discussions. }\end{array}$ & 3 & 9 & $\begin{array}{l}\text { "I didn't like the LMS discussion forums } \\
\text { because we had to write everything down that } \\
\text { we discussed and there were many things that } \\
\text { we skipped in the discussion." }\end{array}$ \\
$\begin{array}{llll}\text { Some communication/coordination } \\
\text { problems with group members } \\
\text { were experienced. }\end{array}$ & 3 & 9 & $\begin{array}{l}\text { "The LMS was good, but there was a problem } \\
\text { about communication. They (group members) } \\
\text { always answered late." }\end{array}$ \\
\hline Total number of responses & 35 & 100 & \\
\hline
\end{tabular}

\section{Respondents' views on their use of the LMS as a course repository}

Participants perceived the LMS as a course repository as the most useful tool in the study: $85 \%$ of them indicated that accessing project resources on demand was very useful. A few students mentioned that using the LMS as a course repository was its best functionality. Some comments cited technical problems in the use of the LMS as a course repository; most of these problems were related to LMS' downloading/uploading performance (Table 3). 
Table 3

Respondents' views on their use of the LMS as a course repository

\begin{tabular}{|c|c|c|c|}
\hline & $\mathrm{n}$ & $\begin{array}{l}\% \text { of } \\
\text { responses }\end{array}$ & Illustrative quotations \\
\hline $\begin{array}{l}\text { The use of the LMS as a course } \\
\text { repository was useful/provided } \\
\text { easy access to the course resources. }\end{array}$ & 29 & 85 & $\begin{array}{l}\text { "The LMS as a course repository was } \\
\text { definitely useful because we always accessed } \\
\text { some important knowledge, and sometimes we } \\
\text { benefited from videos and other files that had } \\
\text { been uploaded by our instructors." } \\
\text { "All the information that we found in the LMS } \\
\text { was very good. Accessing information on } \\
\text { demand is crucial while pursuing a project." }\end{array}$ \\
\hline
\end{tabular}

\begin{tabular}{llll}
\hline $\begin{array}{l}\text { The use of the LMS as a course } \\
\text { repository enabled monitoring } \\
\text { other groups' resources/files. }\end{array}$ & 8 & 24 & $\begin{array}{l}\text { "This is beneficial for us because everyone } \\
\text { can access the projects easily and information } \\
\text { networks can be seen by everyone." }\end{array}$
\end{tabular}

\begin{tabular}{llll}
\hline $\begin{array}{l}\text { Some technical problems (in } \\
\text { downloading/uploading files, etc.) }\end{array}$ & 6 & 18 & $\begin{array}{l}\text { "It is useful as a course repository; however, } \\
\text { the uploading performance of the LMS should } \\
\text { soured the experience. }\end{array}$ \\
& $\begin{array}{l}\text { be improved because we occasionally had } \\
\text { problems when uploading a file." }\end{array}$
\end{tabular}

\begin{tabular}{llll}
\hline $\begin{array}{l}\text { The use of the LMS as a course } \\
\text { repository was its best }\end{array}$ & 3 & 9 & $\begin{array}{l}\text { "The best aspect of the LMS was storing } \\
\text { project-related resources. We easily accessed } \\
\text { functionality. }\end{array}$
\end{tabular}

\begin{tabular}{llll}
\hline $\begin{array}{l}\text { The interface of the LMS course } \\
\text { repository tools was not user- } \\
\text { friendly enough. }\end{array}$ & $3 \quad 9$ & $\begin{array}{l}\text { "I still can't use the LMS as a course } \\
\text { repository properly. It should have been more } \\
\text { user-friendly." }\end{array}$
\end{tabular}

Total number of responses $\quad 34 \quad 100$

\section{Respondents' views on their use of videoconferencing}

Videoconferencing sessions were found to be useful both for exchanging design ideas and interacting with another culture. Several students indicated that the sessions were enjoyable and useful. Freely interacting and being able to see each other during communication were noted as important advantages of the videoconferencing tool. Some students mentioned that oral communication in a foreign language was difficult for them (Table 4). 
Table 4

Respondents' views on their use of videoconferencing

\begin{tabular}{|c|c|c|c|}
\hline & $\mathrm{n}$ & $\begin{array}{l}\% \text { of } \\
\text { responses }\end{array}$ & Illustrative quotations \\
\hline $\begin{array}{l}\text { Videoconferencing sessions were } \\
\text { enjoyable. }\end{array}$ & 12 & 39 & $\begin{array}{l}\text { "Videoconferencing sessions were fun." } \\
\text { "They were really joyful and enjoyable." }\end{array}$ \\
\hline
\end{tabular}

\begin{tabular}{llll}
\hline $\begin{array}{l}\text { Videoconferencing was a more } \\
\text { efficient medium for group }\end{array}$ & 7 & 23 & $\begin{array}{l}\text { "Videoconferencing is easier for group } \\
\text { discussions than the forums." }\end{array}$
\end{tabular}

discussions than the LMS

discussion forums.

\begin{tabular}{|c|c|c|c|}
\hline $\begin{array}{l}\text { Videoconferencing sessions were } \\
\text { useful for interacting with another } \\
\text { culture. }\end{array}$ & 6 & 19 & $\begin{array}{l}\text { "We were able to see another culture and we } \\
\text { learned a lot of things from them." }\end{array}$ \\
\hline $\begin{array}{l}\text { Some technical/connection } \\
\text { problems soured the experience. }\end{array}$ & 6 & 19 & $\begin{array}{l}\text { "There were some parts that I didn't } \\
\text { understand because of the sound system." }\end{array}$ \\
\hline $\begin{array}{l}\text { Communicating in a foreign } \\
\text { language was difficult. }\end{array}$ & 4 & 13 & $\begin{array}{l}\text { "Understanding the foreign language was } \\
\text { hard." }\end{array}$ \\
\hline $\begin{array}{l}\text { Videoconferencing sessions were } \\
\text { good because everybody was able } \\
\text { to see each other. }\end{array}$ & 3 & 10 & $\begin{array}{l}\text { "They were quite good because we could talk } \\
\text { to and see our partners and foreign } \\
\text { instructors." } \\
\text { "They allowed us not only to see the } \\
\text { presentations but enabled us to hear them, } \\
\text { which is really important." }\end{array}$ \\
\hline $\begin{array}{l}\text { The unbalanced number of } \\
\text { participants was a problem. }\end{array}$ & 3 & 10 & $\begin{array}{l}\text { "It would have been better if there were fewer } \\
\text { participants." }\end{array}$ \\
\hline $\begin{array}{l}\text { Videoconferencing sessions were a } \\
\text { new experience. }\end{array}$ & 2 & 6 & $\begin{array}{l}\text { "It was a totally new experience in the } \\
\text { workshop." }\end{array}$ \\
\hline $\begin{array}{l}\text { Videoconferencing sessions should } \\
\text { have been more interactive. }\end{array}$ & 2 & 6 & $\begin{array}{l}\text { "It was useful for us but it should have been } \\
\text { more interactive." }\end{array}$ \\
\hline Total number of responses & 31 & 100 & \\
\hline
\end{tabular}

\section{Respondents' views on traditional studio (face-to-face) teaching}

The majority of students reported that studio discussions were very useful. Some of them stated that traditional face-to-face teaching is an indispensable part of design education. Several students suggested that the traditional studio is more effective for developing a project because it enables them to work on a variety of media and communicate with instructors more easily. There were also some comments indicating that traditional face-to-face teaching is a more-familiar method (Table 5). 
Table 5

Respondents' views on traditional studio (face-to-face) teaching

\begin{tabular}{llll}
\hline & $\mathrm{n}$ & $\begin{array}{l}\% \text { of } \\
\text { responses }\end{array}$ & Illustrative quotations \\
\hline $\begin{array}{l}\text { Studio discussions were very } \\
\text { useful. }\end{array}$ & 20 & 69 & "Studio discussions were really useful." \\
& & &
\end{tabular}
useful.

\begin{tabular}{llll}
\hline Traditional face-to-face teaching is & 7 & 24 & "Offline studio discussions are a must for an \\
an indispensable part of design & & & $\begin{array}{l}\text { interior design student because they improve } \\
\text { our design skills." }\end{array}$
\end{tabular}

Traditional face-to-face teaching is $7 \quad 24 \quad$ "The offline studio is much more effective; more effective for developing a we can discuss more details about our project.

$$
\text { projects." }
$$

"Classroom discussions are the best method for understanding and analyzing projects because you can draw, write anything on papers, and you can communicate with instructors efficiently."

\begin{tabular}{lllll}
\hline $\begin{array}{l}\text { Traditional face-to-face teaching is } \\
\text { a (more) familiar method. }\end{array}$ & 5 & 17 & $\begin{array}{l}\text { "The traditional technique is the most } \\
\text { common method and we are all used to it. It is } \\
\text { beneficial, as we know." }\end{array}$ \\
$\begin{array}{l}\text { Some aspects of the traditional } \\
\text { method were not effective. }\end{array}$ & 4 & 14 & $\begin{array}{l}\text { "Studio works in the traditional studio were } \\
\text { not very good." }\end{array}$ \\
\hline Total number of responses & 29 & 100 & \\
\hline
\end{tabular}

\section{Respondents' views on the comparison between Facebook and the LMS}

Seven groups out of nine (78\%) reported that they used Facebook for project work in the study. The main reason for this utilisation was Facebook's widespread use among the students. Several students indicated that they used Facebook for communication in teamwork because their groupmates checked their Facebook accounts often, while they visited the LMS site only occasionally. The questionnaire responses revealed a major distinction between Facebook and the LMS: a formal-informal dichotomy. While the LMS was perceived as a formal or "academic" tool, Facebook was evaluated as an informal and private one. The outcomes of this difference varied among the students: some preferred the LMS for the course because it is more formal; others favoured Facebook because they found it more intimate (Table 6). 
Table 6

Respondents' views on the comparison between Facebook and the LMS

\begin{tabular}{|c|c|c|c|}
\hline & $\mathrm{n}$ & $\begin{array}{l}\% \text { of } \\
\text { responses }\end{array}$ & Illustrative quotations \\
\hline $\begin{array}{l}\text { We used Facebook in this study } \\
\text { because everyone in our group already } \\
\text { uses it. }\end{array}$ & 13 & 62 & $\begin{array}{l}\text { "We used Facebook to communicate because our } \\
\text { group members check their Facebook accounts } \\
\text { often." }\end{array}$ \\
\hline $\begin{array}{l}\text { The LMS is a formal/academic } \\
\text { communication medium, while } \\
\text { Facebook is an informal one. I } \\
\text { preferred the LMS for this study. }\end{array}$ & 5 & 24 & $\begin{array}{l}\text { "The LMS is an academic platform, so I think it is } \\
\text { more appropriate for this project." } \\
\text { "Discussing our projects with our group in a formal } \\
\text { environment like the LMS is better, but if we'd like } \\
\text { to socialize with some of our group members, } \\
\text { Facebook can be a better choice." }\end{array}$ \\
\hline $\begin{array}{l}\text { I preferred Facebook for this study } \\
\text { because it offers more intimacy. }\end{array}$ & 3 & 14 & $\begin{array}{l}\text { "All of the students in the class can see my } \\
\text { messages in the LMS. I used Facebook because it } \\
\text { is more private." }\end{array}$ \\
\hline $\begin{array}{l}\text { Facebook is easier to use than the } \\
\text { LMS. }\end{array}$ & 3 & 14 & $\begin{array}{l}\text { "When I compare the LMS with Facebook as a } \\
\text { whole, I can say that Facebook is easier to use." }\end{array}$ \\
\hline $\begin{array}{l}\text { Facebook is more enjoyable than the } \\
\text { LMS. }\end{array}$ & 3 & 14 & $\begin{array}{l}\text { "The LMS seems more boring compared to } \\
\text { Facebook. Facebook is fun." } \\
\text { "I like Facebook because I can observe content and } \\
\text { have fun while I am discussing [ideas] with my } \\
\text { team mates." }\end{array}$ \\
\hline $\begin{array}{l}\text { There is no difference between } \\
\text { Facebook and the LMS in terms of } \\
\text { communication and file sharing. }\end{array}$ & 3 & 14 & $\begin{array}{l}\text { "You can share files with the LMS as easily as you } \\
\text { can with Facebook." } \\
\text { "We can discuss projects through the LMS or } \\
\text { Facebook; they are just the same." }\end{array}$ \\
\hline Total number of responses & 21 & 100 & \\
\hline
\end{tabular}

\section{Discussion and conclusions}

This exploratory study provided valuable insights into students' experiences in a blended learning setting. The complementary use of the tools with different representational capabilities and synchronisation modes enabled effective learning processes. The study's blended approach was well accepted by the majority of participants. The most-favourably evaluated tool was the LMS as a course repository. Many students noted that accessing various resources through the LMS was very useful. This finding is probably due to the fact that the knowledge base in soft-applied disciplines tends to be more eclectic (Neumann et al., 2002). Unlike pure courses, which depend on text-book generated materials, applied courses use diversified information from various sources; therefore, the main utility of online tools in soft-applied fields may be to provide access to customised information in an efficient way. This result is similar to that of Smith, Heindel, and Torres-Ayala's study (2008), which analysed LMS tool usage in different disciplines over a five-year period and concluded that the Document tools of LMS' had been increasingly used in applied courses, while hard-pure courses more often utilised Tests and Question Pool tools.

Although all tools were perceived positively in the study, students also made some suggestions to improve them. For example, several participants wanted to include more visual materials in the LMS discussion forums and to be able to modify and annotate documents online. This finding is consistent with previous research that empirically demonstrated the importance of "visual thinking" in design (Pektas, 2010). Project-based discussions within a team entail exchanging a huge amount of information in several different formats (drawings, images, verbal communication, etc.). Moreover, reflection often occurs "in action" (Schön, 1987), while modifying and annotating documents. Therefore, the emphasis in this study on documents and representing domain-specific knowledge indicates that the usefulness of 
online tools in soft-applied disciplines depends largely on the capabilities of such tools in representing, handling, and sharing a variety of customised information.

Soft-applied fields are also characterised by the need for peer and self-assessment, as well as for constructive and interpretative feedback on assessment tasks (Neumann et al., 2002). In this study, the participants often reported that they appreciated the LMS discussion forums and shared online documents because, in the words of one student, "they enabled monitoring and commenting on other groups' processes and files." It has been acknowledged that LMS' facilitate the review and control of learning (Osguthorpe \& Graham, 2003), but this functionality may be more critical in soft-applied fields, where educational processes tend to be more vague and subjective. Our study suggested that online tools that enable learners to record, share, and assess processes efficiently can be appropriate in soft-applied fields. It should be noted that further research is needed to reach more-conclusive results.

Participants also emphasised the advantages of synchronous communication. Some students indicated that they did not like the discussion forums because "they had to write down everything that they discussed." Many participants appreciated the videoconferencing sessions because they were synchronous and enabled direct verbal and visual interaction between group members. Several students indicated that the videoconferencing tool was more efficient for group discussions than the LMS discussion forums. In addition to exchanging technical information, videoconferencing also was perceived useful for interacting with another culture. In the students' evaluations, the videoconferencing facility was the tool acknowledged most often in terms of the benefits of the cultural exchange.

Although many students most preferred the blended-learning aspects of the class, students' views on the traditional studio (face-to-face) teaching were also very positive. Some students even indicated that traditional face-to-face education is an indispensable part of design education and is more effective for developing a project. Paechter and Maier (2010) investigated under what conditions students prefer online or face-to-face learning components in a sample of 2196 students from 29 Austrian universities. The researchers concluded that "[ $t]$ he students preferred face-to-face contact when the discourse with the instructor serves to develop knowledge, e.g., when the instructor is to facilitate the acquisition of knowledge and the application of adequate learning strategies" (p. 296). Neumann et al. (2002) explained that teaching methods in soft-applied disciplines are based on open-ended and constructive discussions with instructors. In design education, an instructor has the traditional role of a facilitator and a demonstrator. The instructor demonstrates problem-solving processes to the students and enables them to acquire necessary information and apply it in different contexts. Therefore, the teaching methods in softapplied disciplines can be an explanation for the current study's participants' positive perceptions about face-to-face learning. Traditional studio (face-to-face) components could also be favoured due to the socialization process in design education. Bliuc, Ellis, Goodyear \& Piggott (2011) discussed that students' learning experiences are considerably influenced by their conceptualisations about what the learning on the subject is supposed to be about. In design education, valuations about the design studio method are transferred from instructors to students in the typical formative process of a soft-applied discipline, which may be another influential factor. The findings of this paper suggest a need for further studies on the relations between delivery modes and disciplinary differences. Research could also analyse which aspects of the traditional (design studio) method are valued by students and how these can be integrated with online learning components.

The use of Facebook in this study was also noteworthy. A review of academic studies about Facebook use reveals that a very small amount of existing Facebook content is educational (Hew, 2011). In our study, the participants used Facebook in various ways, including discussing design content, managing the project, and sharing project files. However, student comparisons of the LMS and Facebook presented conflicting views. Students' perceptions of the LMS as a formal and Facebook as an informal instrument affected their assessments of the tools. Thus, this study suggests that the potential educational uses of Facebook need to be explored with a particular focus on how the informal and social nature of Facebook interacts with the dynamics of teaching and learning.

Design education contains some characteristics of soft-applied disciplines, such as a free-ranging and qualitative knowledge base, a focus on integrating and applying knowledge, and teaching methods based on constructive and open-ended discussions. This study indicates that the features of soft-applied knowledge domains can entail customisation in blended courses in several ways. Online educational 
systems should be flexible enough to accommodate a variety of representations of procedural and declarative knowledge and to enable educators to devise their instructional designs. Further studies on designing and implementing such systems are needed. The disciplinary perspective adopted in this paper can be useful for evaluating online and blended learning in different contexts. For example, further research can focus on the technology affordances of online learning, which might be useful for different disciplines. Identifying ways of working with faculty to develop successful blended approaches in different disciplines is another issue that should be addressed. Comparative studies analysing online and blended learning across multiple disciplinary domains would also be useful. The authors hope that this paper will give rise to further research in this track.

\section{Acknowledgements}

The authors would like to thank the students and instructors who participated in the blended design studio.

\section{References}

Adams, J., Hyde, W., \& Murray, B. (2013). Design education: international perspectives and debates (editorial). International Journal of Art and Design Education, 32(2), 142-145.

Arbaugh, J. B., Bangert, A., \& Cleveland-Innes, M. (2010). Subject matter effects and the Community of Inquiry (CoI) framework: An exploratory study. Internet and Higher Education, 13, 37-44.

Ardaiz-Villanueva, O., Nicuesa-Chacon, X., Brene-Artazcoz, O., Lizarraga, M. L., \& Baquedano, M. T. (2011). Evaluation of computer tools for idea generation and team formation in project-based learning. Computers \& Education, 56, 700-711.

Bender, D. M., \& Vredevoogd, J. D. (2006). Using online education technologies to support studio education. Educational Technology \& Society, 9(4), 114-122.

Biglan, A. (1973). The characteristics of subject matter in different academic areas. Journal of Applied Psychology, 57, 195-213.

Bliuc, A., Ellis, R. A., Goodyear, P., \& Piggott, L. (2011). A blended learning approach to teaching foreign policy: student experiences of learning through face-to-face and online discussion and their relationship to academic performance. Computers \& Education, 56, 856-864.

Ginns, P., \& Ellis, R. A. (2009). Evaluating the quality of e-learning at the degree level in the student experience of blended learning. British Journal of Educational Technology, 40(4), 652-663.

Gürel, M. Ö. (2010). Explorations in teaching sustainable design: a studio experience in interior design/architecture. International Journal of Art \& Design Education, 29(2), 184-199.

Ham J. J., \& Schnabel, M. A. (2011). Web 2.0 virtual design studio: social networking as facilitator of design education. Architectural Science Review, 54, 108-116.

Hew, K. F. (2011). Students' and teachers' use of Facebook. Computers in Human Behavior, 27, 662-676.

Hornik, S., Saunders, C. S., Li, Y., Moskal, P. D., \& Dzuiban, C. D. (2008). The impact of paradigm development and course level on performance in technology-mediated learning environments. Informing Science: The International Journal of an Emerging Discipline, 11, 35-58.

Howsen, R. M., \& Lile, S. (2008). A comparison of course delivery methods: An exercise in experimental economics. Journal of Economics and Finance Education, 7(1), 21-28.

Joy, E. H., \& Garcia, F. E. (2000). Measuring learning effectiveness: A new look at no-significantdifference findings. Journal of Asynchronous Learning Networks, 4(1), 33-39. 
Karakaya, A. F., \& Pektas, S. T. (2007). A framework for web-based education systems supporting interdisciplinary design collaboration. METU Journal of the Faculty of Architecture, 24(2), 137-148. http://jfa.arch.metu.edu.tr/archive/0258-5316/2007/cilt24/sayi_2/137-148.pdf

Kristof, A. L., Brown, K. G., Sims, H. P., \& Smith, K. A. (1995). The virtual team: A case study and inductive model. Advances in Interdisciplinary Studies of Work Teams, 2, 229-53.

Lopez-Perez, M. V., Perez-Lopez, M. C., \& Rodrigues-Ariza, L. (2011). Blended learning in higher education: Students' perceptions and their relation to outcomes. Computers \& Education, 56, 818-826.

Marton, F., \& Booth, S. (1997). Learning and awareness, New Jersey: Lawrence Erlbaum.

Neumann, R. (2001). Disciplinary differences and university teaching. Studies in Higher Education, $26(2), 135-146$.

Neumann, R., Parry, S., \& Becher, T. (2002). Teaching and learning in their disciplinary contexts: A conceptual analysis. Studies in Higher Education, 27(4), 405-417.

Novakova, K., Achten, H., \& Matejovska, D (2010). A design studio pedagogy for experiments in collaborative design, Future Cities: 28th ECAADE Conference Proceedings,. Retrieved March 10, 2012, from http://cumincad.scix.net/cgi-bin/works/Show?ecaade2010_172

Osguthorpe, T. R., \& Graham, R. C. (2003). Blended learning environments. Quarterly Review of Distance Education, 4(3), 227-233.

Paechter, M.,\& Maier, B. (2010). Online or face-to-face? Students experiences and preferences in elearning. Internet and Higher Education, 13, 292-297.

Park, J. Y. (2011). Design education online: learning delivery and evaluation. International Journal of Art \& Design Education, 30(2), 22-33.

Pektas, S. T. (2007). A structured analysis of CAAD education. Open House International, 32(2), 46-54.

Pektas, S. T. (2010). Effects of cognitive styles on 2D drafting and design performance in digital media. International Journal of Technology and Design Education, 20(1), 63-76.

Pektas, S. T., \& Demirkan, H. (2011). Experiences with Moodle as a communication tool for design teamwork: a users' perspective. METU Journal of the Faculty of Architecture, 28(2), 227-241.

Schön, D. (1983). The reflective practitioner: how professionals think in action, New York: Basic Books.

Schön, D. (1987). Educating the reflective practitioner: towards a new design for teaching in the professions, San Francisco: Jossey-Bass.

Schön, D. (1988). Towards a marriage of artistry and applied science in the architectural design studio. Journal of Architectural Education, 41(1), 4-10.

Smith, G. G., Heindel, A. J., \& Torres-Ayala, A. T. (2008). E-learning commodity or community: Disciplinary differences between online courses. Internet and Higher Education, 11, 152-159.

Smith, G. G., Passmore, D., \& Faught, T. (2009). The challenges of online nursing education. Internet and Higher Education, 12, 98-103.

So, H., \& Bonk, C. J. (2010). Examining the roles of blended learning approaches in computer-supported collaborative learning environments: a Delphi study. Educational Technology \& Society, 13(3), 189200. 
Trenholm, S. (2006). An investigation of assessment in fully asynchronous online math courses. International Journal of Educational Integrity, 2(2), 41-55.

Türkkan E. E., Basa I., \& Gürel M. Ö. (2010). The interaction between the design studio and curriculum courses: A Bilkent University Case. Open House International, 35(3), 66-75.

Yang, Y. F., \& Tsai, C. C. (2010). Conceptions of and approaches to learning through online peer assessment. Learning and Instruction, 20, 72-83.

Corresponding author: Şule Taşlı Pektaş, tasli@bilkent.edu.tr

Australasian Journal of Educational Technology (C) 2014.

Please cite as: Pektas, S.T. \& Gürel, M. (2014). Blended learning in design education: An analysis of students' experiences within the disciplinary differences framework. Australasian Journal of Educational Technology, 30(1), 31-44. 